\title{
A Single-Arm, Open-Label, Phase IV Study to Evaluate the Efficacy of a Topical Formulation for Hyperkeratotic Actinic Keratosis Lesions
}

\author{
Maria Pia De Padova - Barbara Marzani - Daniela Pinto • \\ Fabio Rinaldi
}

Received: June 20, 2018 / Published online: July 27, 2018

(C) The Author(s) 2018

\begin{abstract}
Introduction: Actinic keratosis (AKs) are epidermal lesions that commonly occur in skin exposed to chronic cumulative UV irradiation. Untreated AK lesions can advance to squamous cell carcinoma. Current treatments of AK have many shortcomings; for instance, not all treatments can be used for the hyperkeratotic form of AK. The aim of this study was to test the efficacy and tolerability of a topical product containing 2,4,6-octatrienoic acid and urea for the treatment of hyperkeratotic AK lesions.

Methods: Forty male and female subjects with at least two hyperkeratotic AK lesions were enrolled in this single-arm, open-label phase IV study. The product was applied twice daily for two consecutive months. The efficacy endpoints were the reductions in the mean number of AK lesions per subject from baseline (T0) to
\end{abstract}

Enhanced digital features To view enhanced digital features for this article go to https://doi.org/10.6084/ m9.figshare.6809753.

M. P. De Padova

Dermatology, Nigrisoli Private Hospital, Bologna, Italy

B. Marzani · D. Pinto

R\&D, Giuliani SpA, Milan, Italy

F. Rinaldi $(\bowtie)$

International Hair Research Foundation (IHRF),

Milan, Italy

e-mail: fabio.rinaldi@studiorinaldi.com the end of the trial (T1) and to three months after the end of the treatment period (T2).

Results: At T0, the mean (SD) number of lesions per subject was 3.65 (1.25). At the end of the treatment period (T1), this number had dropped (significantly, $p<0.0001$ ) by $83.56 \%$. The mean number of lesions per subject then decreased by $41.47 \%(p<0.0001)$ between $\mathrm{T} 1$ and the three-month follow-up visit (T2). Complete elimination of lesions had occurred in $57.5 \%$ of the subjects at $\mathrm{T} 1$, and $82.5 \%$ (55\% who had remained completely clear of lesions since $\mathrm{T} 1$, and $27.5 \%$ who had fully eliminated their lesions during the period from T1 to T2) at T2. No side effects were reported.

Conclusion: The application of a topical combination of 2,4,6-octatrienoic acid and urea twice daily for 60 consecutive days is a safe and effective treatment for hyperkeratotic $\mathrm{AK}$ lesions.

Funding: Giuliani SpA.

Keywords: Hyperkeratotic actinic keratosis; Keratolytic agent; 2,4,6-octatrienoic acid; Topical treatment; Urea

\section{INTRODUCTION}

The chronic skin condition actinic keratosis (AK) is characterized by intraepithelial atypical proliferation of keratinocytes in sun-exposed skin regions, especially on the face, as well as 
the scalp, ears, forearms, and backs of the hands, although it can also appear on the trunk and legs [1]. AK lesions are considered a clinical sign of the photoaging of photodamaged skin that has undergone subclinical genetic changes: field cancerization $[2,3]$. AK is a worldwide problem with a continuously increasing incidence. In theory, anyone can develop AK, but AK lesions typically arise in immune-compromised patients and in fair-skinned (phototypes I-III) individuals who have undergone excessive and chronic sun exposure and frequent sunburn [4]. AK risk is associated with UV radiation and increases with chronological aging.

$\mathrm{AK}$ lesions are classified using clinical and histological grading systems. Olsen et al. proposed a clinical evaluation of AK lesions based on their thickness: either slightly palpable (grade 1), moderately thick (grade 2), or very thick, hyperkeratotic, and/or obvious (grade 3) lesions [5]. Later, Roewert-Huber and collaborators introduced a histological classification based on atypical keratinocytes in the epidermis: in grade AK I (mild), atypical keratinocytes are restricted to basal and suprabasal layers and limited to the lower third of the epidermis; in grade AK II (moderate), atypical keratinocytes extend to the lower two-thirds of the epidermis; and in grade AK III (severe), full-thickness atypia of the epidermis is present [6]. Unfortunately, these two classification schemes do not correlate well [7]. Although the histological scheme is better at describing and characterizing lesions, the clinical grading scheme is commonly used in clinical practice and in clinical trials (i.e., to determine patient eligibility).

Guidelines recommend that $\mathrm{AK}$ should be treated, even if spontaneous lesion regression is possible $[8,9]$, in order to eliminate visible lesions and subclinical $\mathrm{AK}$ and thus minimize the risk of progression to squamous cell carcinoma (SCC) [10]. There are a number of different treatment options for $\mathrm{AK}$, which can be categorized into two main types: lesion and field-directed therapies. The treatment selection process should consider various factors, including the number of AK lesions (solitary or multiple), their localization and duration, as well as patient age, comorbidities, and treatment compliance. In particular, for some categories of patients (i.e., immunosuppressed patients) and when AK lesions are present in particular body areas (the lips, nose, eyelids, or ears), a more intense therapeutic approach is required [1]. The available therapies are highly effective but, unfortunately, not all of the approved treatments (i.e., ingenol mebutate and imiquimod) are indicated for hyperkeratotic lesions due to the penetration barrier.

For years, the terms "hypertrophic" and "hyperkeratotic" in the treatment guidelines were considered to be synonymous with thicker AK lesions, with no clear distinction between clinical entities $[11,12]$. Recently, however, in an editorial, the expert clinicians of the AKTeam ${ }^{\circledR}$ suggested that the term "hyperkeratotic" should be used for clinically nonsuspicious AK with thick scale [10]. Because the thickness of the lesion is a limiting factor for many treatments, it would be useful to better understand the dimensions of this problem. An Australian cohort study from 2014 reported that up to $25 \%$ of $\mathrm{AK}$ lesions are hyperkeratotic, although this proportion depended on the body area considered: it was $10.3 \%$ of the AK lesions on a bald scalp, $11.5 \%$ of those on the face and ears, $13.7 \%$ of the lesions on the forearms, $16 \%$ of those on the dorsal hands, and $25 \%$ of the AK lesions on the legs [13].

There is no standard therapeutic strategy for hyperkeratotic $\mathrm{AK}$, and the treatment applied can vary with the experience of the physician, the pathology of the lesion, and various patient factors. Multiple methods of enhancing the efficacy of keratosis reduction have been described. Pretreatment with curettage, debulking, tape stripping, as well as microdermabrasion or laser ablation and excisional surgery can be effective approaches for hyperkeratotic lesions [14]. In the case of multiple hyperkeratotic AK lesions, the guidelines propose pretreatment with topical keratolytics and subsequent topical or physical treatment modalities. Salicylic acid and urea are the main topical keratolytic compounds that are used to induce exfoliation of the superficial epidermal layers through the cleavage of corneodesmosomes [15]. This is a simple, atraumatic, 
inexpensive, and painless method of reducing keratosis on photodamaged skin.

Another compound with demonstrated efficacy for photodamaged skin and mild to moderate AK is 2,4,6-octatrienoic acid. Preclinical data published on this parrodiene derivative demonstrate its activity in skin cell lines and a commercial skin model as an endogenous skinprotective agent. Its biological mechanism of action involves PPAR $\gamma$ activation, which helps to reduce oxidative damage and induce DNA repair mechanisms. In UVB-irradiated NHKs post-treated with 2,4,6-octatrienoic acid, the authors observed not only a decrease in the total expression of $\gamma-\mathrm{H} 2 \mathrm{AX}$ with respect to UVBirradiated cells, but also a lower percentage of super-bright-positive cells, i.e., cells in which the cell cycle to repair DNA damage has been arrested [18, 19].

Because data on and treatment options for hyperkeratotic AK lesions are currently lacking, the aim of the study reported in the present paper was to evaluate the safety and efficacy of a topical product containing keratolytic urea and 2,4,6-octatrienoic acid when applied to hyperkeratotic AK lesions.

\section{METHODS}

\section{Study Design}

This study was a spontaneous single-center, single-arm, open-label, phase IV study.

\section{Subjects and Study Assessment}

In the study, 40 subjects with at least two or more clinically hyperkeratotic AK lesions on the face (including the periorbital region, eyelids, ears, and lips) were enrolled. Subjects were asked to avoid using any topical product containing retinoic acid, retinol, vitamin $\mathrm{C}$, salicylic acid, or alpha-hydroxy acids in the treated area one week before and during the entire study period. Subjects were not enrolled if they had actinic keratosis treated with ablative laser within six months of the study, with other topical therapies (including cryotherapy) within three months of the study, or with intense pulsed light treatment within one month of the study. Patients with skin conditions who underwent interventions that could interfere with the diagnosis and/or evaluation of AK were also excluded. Subjects were asked to apply the topical product $(2,4,6$-octatrienoic acid $0.3 \%$ and urea $15 \%$ ) twice daily for two consecutive months. A sunscreen (Lichtena ${ }^{\circledR}$ Dermosolari $50+$ ) was also provided.

Photographs were taken at baseline and at the end of the treatment period. A dermatological evaluation and epiluminescence microscopy analysis (Molemax HD, Derma Medical) were carried out before the treatment (T0), at the end of the treatment period (T1), and after three months of follow-up (T2) to check that the AK had visibly completely cleared. Because defining treatment success as the complete clearance of all AK lesions could underestimate the clinical benefits of treatment in patients with multiple lesions (e.g., the resolution of nine out of ten lesions would be classed as treatment failure, and patients frequently experienced an increase in the lesion count during the study due to the appearance of subclinical lesions), an endpoint of partial clearance $(\geq 75 \%)$ was introduced. Partial clearance is a more clinically powerful endpoint than complete clearance, and has been used in other clinical trials investigating $\mathrm{AK}$ treatments $[16,17]$. Treatment efficacy was therefore measured based on the following clearance percentage scale: partial clearance $(\geq 75 \%)$; mild clearance $(\geq 10 \%$ and $<75 \%)$; minimal to no clearance $(<10)$, i.e., worsened (observable increase in $\mathrm{AK}$ lesions), and unable to be assessed.

\section{Statistical Analysis}

Descriptive statistics (i.e., mean and standard deviation, SD) were calculated for all continuous variables, while frequencies were determined for all categorical variables. Comparisons between visits were performed by means of the two-sample $t$ test. $P$ values of less than 0.05 were considered clinically significant. 


\section{Compliance with Ethics Guidelines}

All procedures followed were in accordance with the Helsinki Declaration of 1964, as revised in 2013. Informed consent was obtained from all patients before they were included in the study.

\section{RESULTS}

A total of 40 subjects ( 26 men and 14 women) with a mean age of $71.075 \pm 7.426$ years and a mean number of AK lesions of $3.650 \pm 1.252$ were enrolled and received treatment (Table 1).

AK lesion clearance was assessed after two months of treatment with 2,4,6-octatrienoic acid and urea (Table 2). Compared to baseline, the treatment reduced the mean number of AK lesions by $83.56 \%$, from 3.650 at baseline to 0.600 at the end of the treatment period $(P<0.0001)$ (Fig. 1$)$. The AK count after three months of follow-up showed a reduction in the number of AK lesions since the end of the treatment period of $41.47 \% \quad(p<0.0001)$ (Fig. 1).

Table 1 Subject characteristics

\begin{tabular}{ll}
\hline Demographic & $\begin{array}{l}\text { Subjects }(\boldsymbol{N}=\mathbf{4 0}), \\
\boldsymbol{n}(\%)\end{array}$ \\
\hline Men $(n, \%)$ & $26(65 \%)$ \\
Women $(n, \%)$ & $14(35 \%)$ \\
Age (years, mean \pm DS) & $71.075 \pm 7.426$ \\
No. of AK lesions $(n$, mean \pm DS) & $3.650 \pm 1.252$ \\
\hline
\end{tabular}

Table 2 AK treatment efficacy at T1

\begin{tabular}{ll}
\hline Proportion of AK lesions cleared & $\begin{array}{l}\text { Subjects } \\
(\boldsymbol{N}=\mathbf{4 0}), \boldsymbol{n}(\%)\end{array}$ \\
\hline Complete clearance $(100 \%)$ & $23(57.5 \%)$ \\
Partial clearance $(\geq 75 \%$, including & $32(80 \%)$ \\
subjects with complete clearance) & \\
Mild clearance ( $\geq 10$ and $<75 \%)$ & $6(15 \%)$ \\
No clearance & $2(5 \%)$ \\
\hline
\end{tabular}

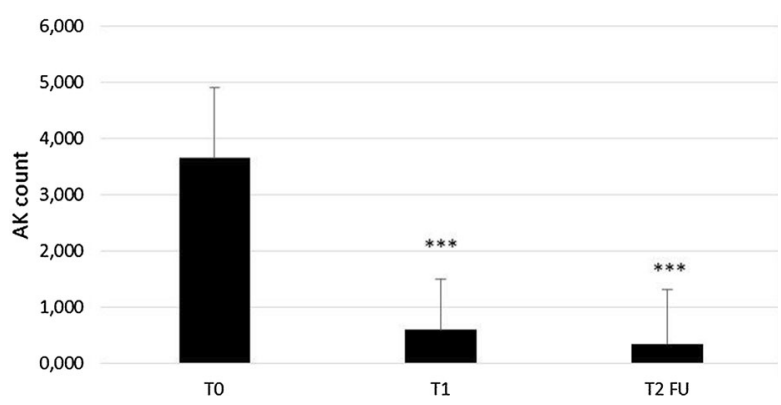

Fig. 1 Mean number of AK lesions per subject before treatment (T0, baseline), at the end of the treatment period (T1), and at the three-month follow-up visit (T2 FU). ${ }^{* * *} p<0.0001$ vs T0

Table 2 shows that 23 subjects $(57.5 \%$ of all subjects) presented complete clearance of all AK lesions at T1. Partial clearance $(\geq 75 \%$ of all lesions cleared; including patients with complete clearance) was observed in 32 patients (80\%), while mild clearance was seen in six subjects $(15 \%)$. No clearance was reported in two patients.

During the three-month follow-up visit, $82.5 \%$ of the subjects showed total clearance, as the AK lesions had completely cleared during the period from $\mathrm{T} 1$ to $\mathrm{T} 2$ in 11 patients (Table 3). New AK lesions were observed in four subjects at $\mathrm{T} 2$.

Some representative images before treatment and at the end of treatment are shown in Fig. 2.

In general, no side effects were reported, even during treatment of the periorbital region (Fig. 2).

Table 3 AK treatment efficiency at T2

\begin{tabular}{|c|c|}
\hline AK lesion status & $\begin{array}{l}\text { Subjects } \\
(N=40), n(\%)\end{array}$ \\
\hline Complete clearance $(100 \%)$ & $33(82.5 \%)$ \\
\hline $\begin{array}{l}\text { Complete clearance maintained from } \\
\text { T1 }\end{array}$ & $22(55 \%)$ \\
\hline $\begin{array}{l}\text { Complete clearance achieved during } \\
\text { period from } \mathrm{T} 1 \text { to } \mathrm{T} 2\end{array}$ & $11(27.5 \%)$ \\
\hline New AK lesions observed at T2 & $4(10 \%)$ \\
\hline
\end{tabular}




\section{a}

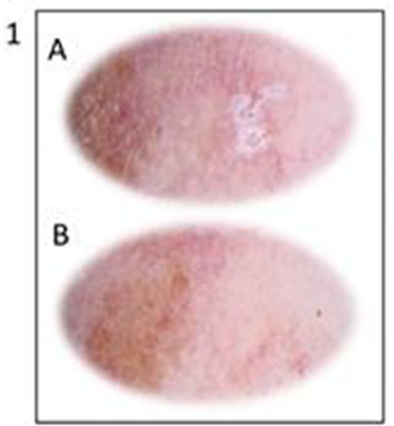

2
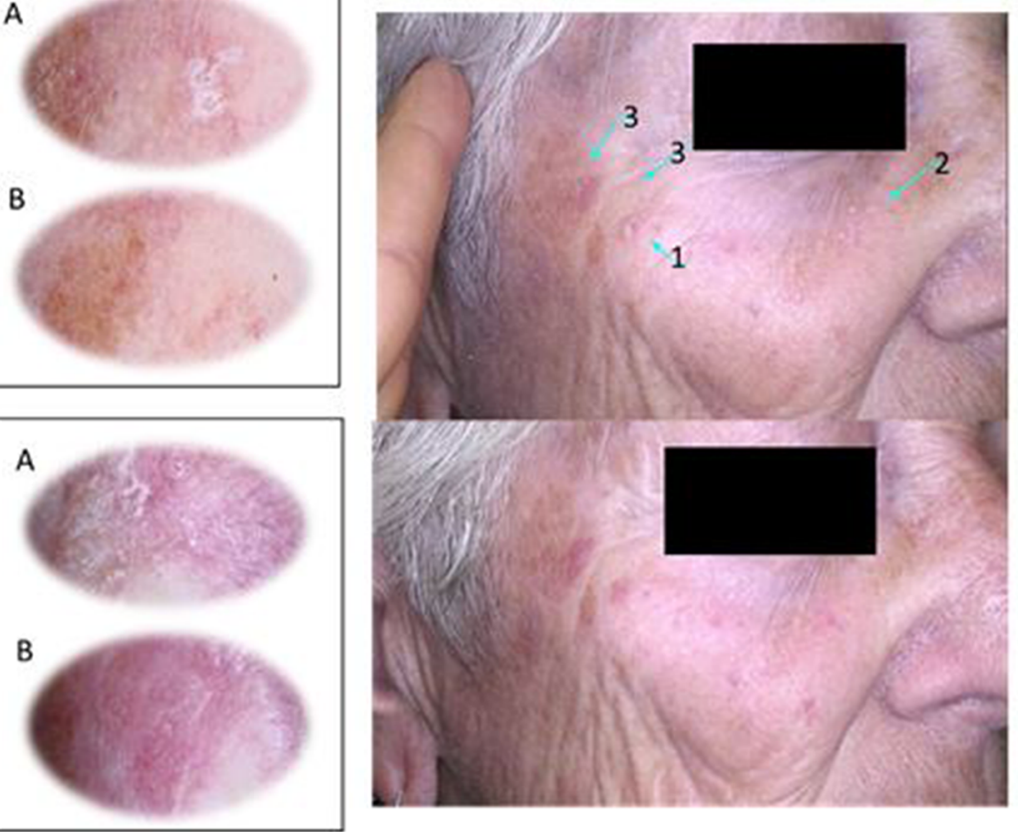

3

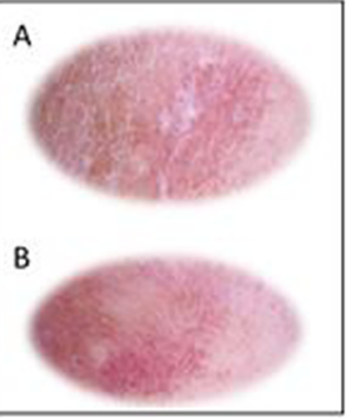

b

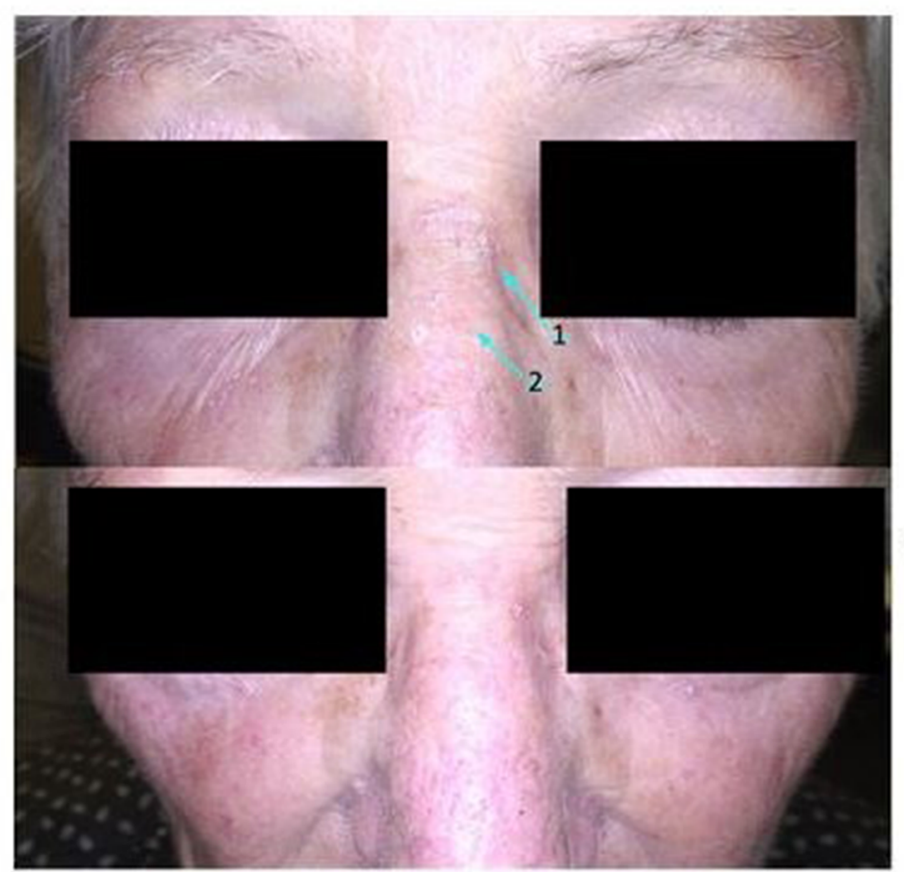

1 A

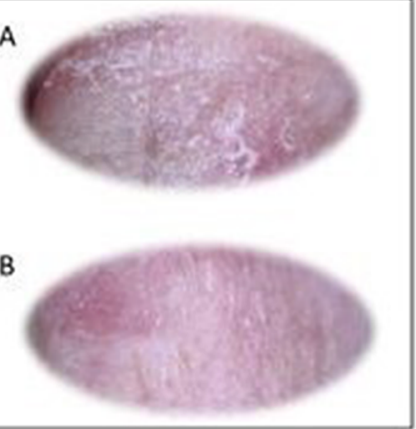

2 A

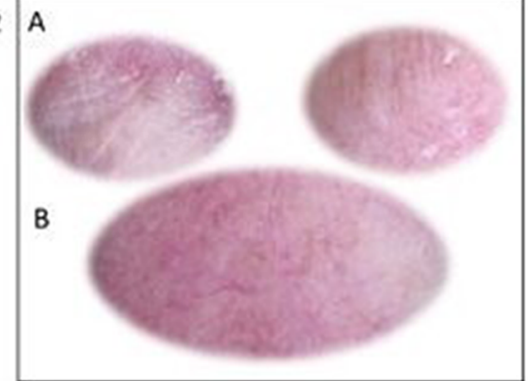

Fig. 2a-b Representative images of two subjects (a and $\mathbf{b})$ at baseline $(\mathbf{A})$ and at the end of the treatment period (B) 


\section{DISCUSSION}

$\mathrm{AK}$ is very common, and there is a risk that untreated lesions will progress to SCC. Many therapies for actinic keratosis are tolerated well and produce excellent outcomes, but only a few of those can be used for hyperkeratotic AK. Treatment efficacy depends strongly on the penetration of the topical drug into the epidermis. As actinic keratosis lesions are commonly hyperkeratotic, they can be difficult to penetrate, so the use of a keratolytic agent is highly recommended.

Recently, some studies have reported the efficacy of a product containing 2,4,6-octatrienoic acid for the prevention and treatment of nonhyperkeratotic actinic keratosis lesions [20]. The presence of a hyperkeratotic lesion has usually been an exclusion criterion in relevant clinical trials, so few studies have addressed this type of lesion. Available methods of treating hyperkeratotic AK lesions show some disadvantages, such as pain, discomfort, possible infections, and hypo- or hyper-pigmentation in the case of curettage or excision. Chemical keratolytic agents present a better safety profile.

The combination of 2,4,6-octatrienoic acid with urea should be a treatment option for hyperkeratotic AK lesions. Subjects with two or more AK lesions treated twice daily with 2,4,6-octatrienoic acid and urea for 60 consecutive days showed a significant reduction in the number of lesions, with complete clearance of lesions observed by the end of the treatment period in $55 \%$ of the subjects and complete clearance achieved in $27.5 \%$ of subjects during the first three months after the treatment period (i.e., the follow-up period). The present study showed that hyperkeratotic AK lesions can be cleared through the topical application of 2,4,6-octatrienoic acid and urea. This topical formulation was tolerated well during the two-month treatment period, including when it was used in the periorbital area, and no adverse effects of this treatment were reported.

\section{Limitations}

A major limitation/shortcoming of the current study is that our evaluation includes the results of applying a no-drug treatment in a small number of subjects. Moreover, in an attempt to perform the investigation under real-life conditions, subjects from the same region of Italy were chosen for the study. A future study with a shorter treatment period, a longer follow-up period, and larger clinical trials should more accurately establish the efficacy of this alternative treatment.

\section{CONCLUSIONS}

In conclusion, 2,4,6-octatrienoic acid and urea twice daily for 60 consecutive days was found to be a safe and effective alternative treatment for hyperkeratotic AK lesions.

\section{ACKNOWLEDGEMENTS}

We thank the participants of the study.

Funding. The study and article processing charges were funded by Giuliani SpA. All authors had full access to all of the data in this study and take complete responsibility for the integrity of the data and the accuracy of the data analysis.

Authorship. All named authors meet the International Committee of Medical Journal Editors (ICMJE) criteria for authorship for this manuscript, take responsibility for the integrity of the work as a whole, and have given final approval for the version to be published.

Disclosures. B. Marzani is a full-time employee of Giulini SpA. D. Pinto is a full-time employee of Giuliani SpA. M.P. De Padova and F. Rinaldi have nothing to disclose.

Compliance with Ethics Guidelines. All procedures followed were in accordance with the Helsinki Declaration of 1964, as revised in 2013. Informed consent was obtained from all patients before they were included in the study.

Data Availability. The datasets used and/or analyzed during the current study are available from the corresponding author on reasonable request. 
Open Access. This article is distributed under the terms of the Creative Commons Attribution-NonCommercial 4.0 International License (http://creativecommons.org/licenses/ by-nc/4.0/), which permits any noncommercial use, distribution, and reproduction in any medium, provided you give appropriate credit to the original author(s) and the source, provide a link to the Creative Commons license, and indicate if changes were made.

\section{REFERENCES}

1. Richard MA, Amici JM, Basset-Seguin N, Claudel JP, Cribier B, Dreno B. Management of actinic keratosis at specific body sites in patients at high risk of carcinoma lesions: expert consensus from the AKTeam $^{\mathrm{TM}}$ of expert clinicians. J Eur Acad Dermatol Venereol. 2018;32(3):339-46.

2. Werner RN, Sammain A, Erdmann R, Hartmann V, Stockfleth E, Nast A. The natural history of actinic keratosis: a systematic review. $\mathrm{Br} \mathrm{J}$ Dermatol. 2013;169(3):502-18.

3. Goldenberg G. Treatment considerations in actinic keratosis. J Eur Acad Dermatol Venereol. 2017;31(Suppl 2):12-6.

4. Cantisani C, De Gado F, Ulrich M, Bottoni U, Iacobellis F, Richetta AG, Calvieri S. Actinic keratosis: review of the literature and new patents. Recent Pat Inflamm Allergy Drug Discov. 2013;7(2):168-75.

5. Olsen EA, Abernethy ML, Kulp-Shorten C, Callen JP, Glazer SD, Huntley A, McCray M, Monroe AB, Tschen E, Wolf JE Jr. A double-blind, vehicle-controlled study evaluating masoprocol cream in the treatment of actinic keratoses on the head and neck. J Am Acad Dermatol. 1991;24(5 Pt 1):738-43.

6. Roewert-Huber J, Stockfleth E, Kerl H. Pathology and pathobiology of actinic (solar) keratosis-an update. Br J Dermatol. 2007;157(Suppl 2):18-20.

7. Schmitz L, Kahl P, Majores M, Bierhoff E, Stockfleth E, Dirschka T. Actinic keratosis: correlation between clinical and histological classification systems. J Eur Acad Dermatol Venereol. 2016;30(8):1303-7.

8. Marks R, Foley P, Goodman G, Hage BH, Selwood TS. Spontaneous remission of solar keratoses: the case for conservative management. Br J Dermatol. 1986;115(6):649-55.
9. Frost C, Williams G, Green A. High incidence and regression rates of solar keratoses in a Queensland community. J Invest Dermatol. 2000;115(2):273-7.

10. Dréno B, Amici JM, Basset-Seguin N, Cribier B, Claudel JP. Richard MA; AKTeam ${ }^{\mathrm{TM}}$. Management of actinic keratosis: a practical report and treatment algorithm from AKTeam ${ }^{\mathrm{TM}}$ expert clinicians. J Eur Acad Dermatol Venereol. 2014;28(9):1141-9.

11. Bonerandi JJ, Beauvillain C, Caquant L, Chassagne JF, Chaussade V, Clavère $P$, Desouches C, Garnier F, Grolleau JL, Grossin M, Jourdain A, Lemonnier JY, Maillard H, Ortonne N, Rio E, Simon E, Sei JF, Grob JJ, Martin L, French Dermatology Recommendations Association (aRED). Guidelines for the diagnosis and treatment of cutaneous squamous cell carcinoma and precursor lesions. J Eur Acad Dermatol Venereol. 2011;25(Suppl 5):1-51.

12. Uhlenhake EE, Sangueza OP, Lee AD, Jorizzo JL. Spreading pigmented actinic keratosis: a review. J Am Acad Dermatol. 2010;63(3):499-506. https:// doi.org/10.1016/j.jaad.2009.07.026.

13. Tan JM, Sinnya S, Soyer HP. The ratio of non-hyperkeratotic and hyperkeratotic actinic keratosis in a high-risk non-melanoma skin cancer cohort in Queensland. J Eur Acad Dermatol Venereol. 2016;30(3):473-4.

14. Morton CA, Szeimies RM, Sidoroff A, Braathen LR. European guidelines for topical photodynamic therapy part 1: treatment delivery and current indications-actinic keratoses, Bowen's disease, basal cell carcinoma. J Eur Acad Dermatol Venereol. 2013;27(5):536-44.

15. Chetty P, Choi F, Mitchell T. Primary care review of actinic keratosis and its therapeutic options: a global perspective. Dermatol Ther (Heidelb). 2015;5(1):19-35.

16. Korman N, Moy R, Ling M, Matheson R, Smith S, McKane S, Lee JH. Dosing with 5\% imiquimod cream 3 times per week for the treatment of actinic keratosis: results of two phase 3 , randomized, double-blind, parallel-group, vehicle-controlled trials. Arch Dermatol. 2005;141(4):467-73.

17. Szeimies RM, Gerritsen MJ, Gupta G, Ortonne JP, Serresi S, Bichel J, Lee JH, Fox TL, Alomar A. Imiquimod $5 \%$ cream for the treatment of actinic keratosis: results from a phase III, randomized, doubleblind, vehicle-controlled, clinical trial with histology. J Am Acad Dermatol. 2004;51(4):547-55.

18. Briganti S, Flori E, Bellei B, Picardo M. Modulation of PPAR $\gamma$ provides new insights in a stress induced premature senescence model. PLoS One. 2014;9(8):e104045. 
19. Flori E, Mastrofrancesco A, Kovacs D, Bellei B, Briganti S, Maresca V, Cardinali G, Picardo M. The activation of PPAR $\gamma$ by 2,4,6-octatrienoic acid protects human keratinocytes from UVR-induced damages. Sci Rep. 2017;7(1):9241.
20. Lombardi M, Rossi A, Fortuna MC, Garelli V, Sama E, Senis D, et al. Treatment of facial actinic keratoses with a cream containing octatrienoic acid: a multi center clinical experience. G Ital Dermatol Venereol. 2018. https://doi.org/10.23736/S0392-0488.18.06064-9. 